\title{
Evaluation of retention of dental students' trauma knowledge following a reminder lecture.
}

\author{
Meric Karapinar-Kazandag1, Jale Tanalp ${ }^{1}$, Tuba Ayhan', Rabia Figen Kaptan', Handan Ersev ${ }^{2 *}$ \\ ${ }^{1}$ Department of Endodontics, Faculty of Dentistry, Yeditepe University, İstanbul, Turkey \\ ${ }^{2}$ Department of Endodontics, Faculty of Dentistry, İstanbul University, İstanbul, Turkey
}

\begin{abstract}
Aim: The aim of this study was to assess senior dental students' acquisition of knowledge after 3 months following a reminder lecture.

Materials and methods: A $1 \mathrm{~h}$ lecture including a slide presentation was prepared according to the Guidelines of International Association of Dental Traumatology (IADT). The participants were asked to fill-out a questionnaire of 31 questions before (T0), after (T1) and 3 months (T2) after the lecture and were given $15 \mathrm{~min}$ for the completion of each questionnaire. Statistical significance level was set at $\mathbf{P}<0.05$.

Results: The average percentage of correct answers was higher after lecture than before $(P<0.05)$ and there was some retention of knowledge after three months $(\mathrm{P}<0.05)$. The information was more retentive when delivered in the second part of the lecture $(P<0.05)$ and for the students who encountered no trauma cases previously, whereas there was no difference between genders.

Conclusions: One-hour reminder lecture on trauma just before graduation is beneficial for dental students. Provision of students with take home messages in the last part of the lecture can be recommended as information seems more retentive when delivered at this stage. The students who encountered no trauma cases previously may benefit more from a $1 \mathrm{~h}$ reminder lecture.
\end{abstract}

Keywords: Dental education, Knowledge retention, Teaching assessment.

Accepted on December 4, 2017

\section{Introduction}

Traumatic dental injury is a general name given to impacts to teeth as well as other hard and soft tissues neighboring the mouth and the oral cavity. It is a sudden incident which requires emergency intervention in most cases. One of the most striking consequences of dental trauma is the life-changing dental procedures performed on an individual who otherwise has perfect oral hygiene and only has to visit the dentist for regular check-ups [1]. One of the most common types of health problems in public is traumatic dental injuries. Although differences exist with respect to geographic origin, a general statistical result is that one-third of preschool children, onefourth of school children and one-third of adults sustained dental trauma [2].

Dental trauma may lead to a wide range of complications including loss of tooth vitality, occurrence of periapical disease, esthetic disorders or the necessity of extraction [3]. It has been indicated that victims of traumatic incidents have certain expectations from the dental practitioners among which alleviation of pain and suffering as well as successful management of the compromised tooth are the foremost. Furthermore; adequate management should be provided to ensure a successful long-term prognosis [4,5]. It has been reported that dental trauma should be considered as an important issue related with public health as it has significant impacts on economy and overall life quality [1]. The economic influences of trauma on the victim as well as the community are of extensive magnitude [6-10]. This is not only related with the physical or economic issues associated with the traumatic incident but also with the psychological and social impact on the individual [1]. Consequently, dental trauma is a frequently encountered incident that is problematic not only to the affected individual but also on the society in general [11-14].

Whilst management of dental trauma is a very serious issue that needs to be dealt with care by the dental practitioners, some studies have shown significant inadequacy in the delivery of appropriate care [15] whereas others have shown reluctance of patients in receiving dental treatment for traumatized teeth [16]. This necessitates dental practitioners to be well-equipped with sufficient knowledge and experience in the first-aid and management of dental traumatic injuries. Furthermore; the dental practitioner should possess a fundamental knowledge and understanding of dental trauma as well as awareness on personal limitations to be able to refer the patient to the relevant specialists when confronted with cases beyond his/her expertise. 
The level of competencies that a dental student is expected to have acquired prior to graduation has been well-defined by the guidelines released by acknowledged organizations. According to the "Profile and Competencies for the Graduating European Dentist-Update 2009, the dental student must be competent in identifying and managing dental emergencies including those of pulpal, periodontal or traumatic origin, providing urgent dental treatment of traumatic uncomplicated dental injuries in deciduous and permanent dentitions or referring appropriately the more severe cases to specialist or Child Care Services and management of trauma in deciduous and permanent dentitions. The graduating dentist is further expected to be familiar with the surgical and non-surgical aspects of the management of maxillofacial trauma [17]. The American Dental Education Association (ADEA) Competencies for the New General Dentist also underlines that the graduates must be competent in the prevention, identification, and management of trauma, oral diseases, and other disorders (ADEA Competencies for the New General Dentist-as approved by the 2008 ADEA House of Delegates). The opportunity of a dental student to encounter a traumatic injury during undergraduate education depends on a variety of factors such as the location of the dental school, the dental requirements of the community in the vicinity of the dental school and the triage plan of the institution; therefore, it is likely that the student is not able to manage or even observe the management of a traumatic dental injury during the educational period. Meanwhile, in the majority of the cases, traumatic incidents are managed by specialists or post-graduate students, leaving the dental students with very little opportunity to be directly involved in the treatment process to acquire sufficient clinical competency prior to graduation. Some authors indicated that outreach training might be one way to resolve this issue and training of students in areas other than the dental school might result in boosting the selfconfidence of students and generation of better treatment plans $[18,19]$. However, this strategy is not yet implemented in Turkey and students and educators are still dependent upon what is received during the educational period spent at the dental school when trauma knowledge is concerned. In the Dental School where this study is conducted, dental traumatology course is delivered as a multidisciplinary module during the $4^{\text {th }}$ year with the collaboration of multiple departments including Pediatric Dentistry, Endodontics, Restorative Dentistry, Prosthodontics, Maxillofacial Surgery and Periodontology. These individual departments that deliver information from their own perspective divide the course, thus unnecessary repetition is avoided. The final acquired knowledge and skill of the student in terms of dental trauma is highly dependent on the theoretical information received during this course, thus instillation and preservation of satisfactory knowledge during this period is of utmost importance to display the correct professional attitude during independent practice following graduation.

Studies that aim to assess the general knowledge of dentists on the diagnosis and management of dental trauma revealed that dental practitioners lack sufficient knowledge regarding the identification and treatment of dental traumatic injuries
[15,20-23]. A survey on Turkish dentists has also given similar results [24]. Dental trauma is a specific incident which incorporates varying types of management. It is an untimely occurrence which in most cases shows up with an unscheduled visit. Additionally, the management of the traumatic cases carry inherent risks such as lack of diagnostic certainty and the necessity of patient follow-up for an extended period of time. The impact of patient's surroundings as well as his/her own characteristic factors should also not be overlooked; thus every case is specific and unique in the way it presents [1]. Consequently, adequate knowledge in dental trauma including diagnosis and management will have many positive influences on the victim and his/her family as well as the dental practitioner and increase the level of success of the prognosis of the case [24-26].

To the authors' knowledge, there is yet no published study that investigates the knowledge of Turkish dental students on dental trauma. On the other hand, little information exists on the knowledge of undergraduate dental students on the management of dental trauma and how a theoretical reminder lecture will contribute to overall knowledge prior to graduation. The positive influences and appropriateness of repetitive dental trauma lectures is definitely a topic that should be evaluated and consolidated, because data obtained from such research will significantly contribute to the development of educational programs and consequently prognosis improvement [27]. Furthermore, the increase in the number of such investigations will support the view that a general necessity arises as to focus more on the delivery of adequate information on dental trauma to dental students who are on the verge of serving the community.

The purpose of this study was to evaluate the level of knowledge of the 5th year dental students who received the Dental Traumatology course in the previous year, to assess the effect of refreshment of knowledge a few months before graduation and understand whether such a repetitive training will contribute to students' knowledge retention which might have an impact on overall performance during independent practice.

The following information was expected to be provided by the results of the study:

1) The level of knowledge of senior dental students who received dental trauma education in the previous year.

2) Student acquisition of knowledge after a $1 \mathrm{~h}$ reminder lecture.

3) The retention of knowledge 3 months after the lecture.

4) Any difference between the $1^{\text {st }}$ and $2^{\text {nd }}$ halves of the lecture at the time points mentioned above.

5)Any difference between genders at the time points mentioned above. 


\section{Materials and Methods}

This study was approved by the Institutional Review Board of Yeditepe University, Istanbul, Turkey. A study was conducted among the senior dental students of Yeditepe University, Faculty of Dentistry, Istanbul, Turkey. Prior to the study, signed informed consent forms were received from all participants who volunteered. A $1 \mathrm{~h}$ lecture including a slide presentation was prepared according to the Guidelines of International Association of Dental Traumatology (IADT) [28,29]. Meanwhile, a questionnaire was prepared which included 32 questions related with dental trauma and based on the prepared lecture. In the first part of the questionnaire, students were asked to indicate whether they previously observed any case of dental traumatic injury at the clinics. The remaining 31 questions were prepared to assess students' knowledge on dental trauma. Thirty of the questions were multiple-choice whereas only one question was prepared in the fill-in the-blank mode.

The participants were presented with 2 attached copies of the questionnaire, one to be filled out before (T0) and the other (T1) to be completed after the lecture. After the completion of the first copy of the questionnaire (T0), the previously prepared $1 \mathrm{~h}$ lecture was given by one of the faculty members of the Department of Endodontics. The lecture included all aspects of dental traumatology by taking the IADT guidelines [28,29] as the reference. The participants were asked to complete the second copy of the questionnaire immediately after the lecture (T1). For the assessment of the retention of acquired knowledge, the participants were invited to complete the same questionnaire 3 months later (T2). Consequently, the students were given the questionnaire a total of 3 times and a $15 \mathrm{~min}$ time for the completion of each questionnaire.

The normal distribution of the answers given by the participants was assessed using the Shapiro-Wilk test, Histogram and normal QQ pilot. It was observed that the ratio of wrong answers in "fill-in-the blanks" type of question was considerably high; therefore this part of the questionnaire was excluded. Statistical analysis was performed using the IBM SPSS Statistics 22 (IBM SPSS, Turkey) program. The conformity of parameters to normal distribution was assessed using Shapiro-Wilk test which revealed that there was nonconformity in terms of distribution. Friedman and Wilcoxon sign tests were used for the comparisons of the average percentages of correct answers at T0 (before the lecture), T1 (immediately after the lecture) and T2 (3 months after the lecture) within groups, whereas the inter-group comparisons of average percentages of correct answers at T0-T2 and their differences were performed using Mann Whitney $U$ test. Statistical significance level was set at $\mathrm{P}<0.05$.

\section{Results}

Thirty-five $(67 \%)$ of the senior students accepted to participate in the study. All these students completed the initial questionnaires before and immediately after the lecture; however 5 students failed to attend the completion of the questionnaire 3 months later, leaving a total of 30 students to be evaluated. Twenty-three $(76.7 \%)$ of these participants were females whereas $7(23.3 \%)$ were males. Six $(20 \%)$ of the participants reported that they previously had the chance to observe dental traumatic injuries at the student clinic.

The Friedman test and post-hoc Wilcoxon sign test showed statistically significant differences between the average percentages of correct answers at T0-T2 (P: 0.001; $\mathrm{P}<0.05)$ (Table 1).

Based on the Mann Whitney U test evaluations, no statistically significant differences were observed between genders in terms of the average percentages of correct answers given at T0-T2 $(\mathrm{P}>0.05)$. Furthermore, no significant differences were noted in the differences between the average percentages of correct answers between genders in all retesting periods $(\mathrm{P}>0.05)$ (Table 2).

Based on the Wilcoxon sign test evaluations, the increase in the average percentage of correct answers immediately after the lecture compared to pre-lecture questionnaire was statistically significant for both genders $(\mathrm{P}<0.05)$. The increase in the average percentage of correct answers 3 months after the lecture compared to pre-lecture questionnaire was also statistically significant for both genders $(\mathrm{P}<0.05)$. On the other hand, a reduction in the average percentage of correct answers was observed in the 3-month questionnaire compared to the questionnaire given immediately after the lecture, which was statistically significant for both genders $(\mathrm{P}<0.05)$ (Table 2$)$.

When the average percentages of correct answers of students who encountered with trauma cases previously were statistically evaluated with the Wilcoxon sign test, the average percentage obtained before the lecture was not significantly different from those observed immediately after and 3 months after the lecture $(\mathrm{P}>0.05)$. A decrease was observed between the average percentage of correct answers in the questionnaire given 3 months later compared to the questionnaire given immediately after the lecture, however the difference was not statistically significant $(\mathrm{P}>0.05)$ (Table 3$)$.

When students with no previous experience were assessed, the Wilcoxon sign test showed that the increases in the average percentages of correct answers in the questionnaires given immediately and 3 months after the lecture compared to that conducted before the lecture were statistically significant $(\mathrm{P}<0.05)$. On the other hand, a decrease was observed in terms of the average percentage of correct answers in the questionnaire given after 3 months compared to the one performed immediately after the lecture with a statistically significant difference (P: 0.001; $\mathrm{P}<0.05$ ) (Table 3).

The Mann Whitney U test indicated no statistically significant differences between T0, T1 and T2 scores for the questions related to the first part (slides 1-40) and the second part (slides 41-80) of the lecture ( $\mathrm{P}>0.05)$ (Table 4$)$.

Based on the Wilcoxon sign test evaluations, in regard to the first part of the lecture, there was an increase at $\mathrm{T} 1$ when compared to T0 (P: $0.008 ; \mathrm{P}<0.05)$. The increase at T2 when 
compared to T0 was not statistically significant (P: 0.125 ; $\mathrm{P}>0.05)$. There was a decrease at $\mathrm{T} 2$ when compared to T1 ( $\mathrm{P}$ : $0.021 ; \mathrm{P}<0.05)$ (Table 4). In regard to the second part of the lecture, there was an increase at T1 when compared to T0 (P: $0.004 ; \mathrm{P}<0.05)$. There was an increase at $\mathrm{T} 2$ when compared to T0 (P: $0.016 ; \mathrm{P}<0.05)$. There was a decrease at $\mathrm{T} 2$ when compared to T1 (P: 0.030; $\mathrm{P}<0.05)$ (Table 4).

Table 1. Statistical comparison of the average percentages of correct answers (\%) at the three time points.

\begin{tabular}{|c|c|}
\hline & Aver \pm SD (median) \\
\hline T0 & $46.33 \pm 8.32(43.3)$ \\
\hline $\mathrm{T} 1$ & $73.33 \pm 16.91(73.3)$ \\
\hline $\mathrm{T} 2$ & $58.89 \pm 8.13(60)$ \\
\hline $\mathrm{P} 1$ & $0.001^{*}$ \\
\hline T0/T1 & $\mathrm{P} 2: 0.001^{*}$ \\
\hline $\mathrm{TO} / \mathrm{T} 2$ & P2: $0.001^{*}$ \\
\hline $\mathrm{T} 1 / \mathrm{T} 2$ & $P 2: 0.001^{*}$ \\
\hline \multicolumn{2}{|r|}{$\begin{array}{l}{ }^{1} \text { Friedman test; }{ }^{2} \text { Wilcoxon sign test; }{ }^{*} p<0.05 \text {. Aver: Average; SD: Standard } \\
\text { Deviation; T0: before the lecture; T1: immediately after the lecture; T2: three } \\
\text { months after the lecture. }\end{array}$} \\
\hline
\end{tabular}

Table 2. Statistical comparison of the average percentages of correct answers (\%) at the three time points and their differences according to gender.

\begin{tabular}{llll}
\hline & Gender & P1 \\
\cline { 2 - 3 } & Male Aver \pm SD (median) & Female Aver \pm SD (median) & 0.843 \\
\hline T0 & $45.71 \pm 8.32(43.3)$ & $46.52 \pm 8.5(43.3)$ & 0.863 \\
\hline T1 & $74.29 \pm 5.68(76,7)$ & $73.04 \pm 19.17(73.3)$ & 0.805 \\
\hline T2 & $60 \pm 8.16(56.7)$ & $58.55 \pm 8.28(60)$ & \\
\hline T0/T1 & P2: $0.018^{*}$ & P2: $0.001^{*}$ & \\
\hline T0/T2 & P2: $0.027^{*}$ & P2: $0.001^{*}$ & 0.941 \\
\hline T1/T2 & P2: $0.018^{*}$ & P2: $0.005^{*}$ & 0.444 \\
\hline T1-T0 & $28.57 \pm 9.59(26.7)$ & $26.52 \pm 20.11(30)$ & 0.461 \\
\hline T2-T0 & $14.29 \pm 11.01(20)$ & $12.03 \pm 10.43(10)$ & \\
\hline T2-T1 & $-14.29 \pm 8.54(-13.3)$ & $-14.49 \pm 19.56(-16.7)$ & \\
\hline
\end{tabular}

${ }^{1}$ Mann Whitney $U$ test; ${ }^{2}$ Wilcoxon sign test; ${ }^{*} p<0.05$. Aver: Average; SD Standard Deviation; T0: before the lecture; T1: immediately after the lecture; T2: three months after the lecture.

Table 3. Statistical comparison of the average percentages of correct answers (\%) at the three time points and their differences according to previous experience on trauma.

\begin{tabular}{|c|c|c|c|}
\hline & \multicolumn{2}{|l|}{ Previous experience } & \multirow[t]{2}{*}{ P1 } \\
\hline & Yes & No & \\
\hline & Aver \pm SD (median) & Aver \pm SD (median) & \\
\hline T0 & $45.56 \pm 11.67(46.7)$ & $46.53 \pm 7.58(43.3)$ & 0.753 \\
\hline
\end{tabular}

\begin{tabular}{llll}
\hline T1 & $71.11 \pm 27.54(73.3)$ & $73.89 \pm 13.92(73.3)$ & 0.855 \\
\hline T2 & $60 \pm 10.11(58.3)$ & $58.61 \pm 7.8(60)$ & 0.834 \\
\hline T0/T1 & P2: 0.092 & P2: $0.001^{*}$ & \\
\hline T0/T2 & P2: 0.058 & P2: $0.001^{*}$ & \\
\hline T1/T2 & P2: 0.345 & P2: $0.001^{*}$ & 0.55 \\
\hline T1-T0 & $25.56 \pm 31.6(36.7)$ & $27.36 \pm 13.94(28.3)$ & 0.514 \\
\hline T2-T0 & $14.45 \pm 12.77(18.3)$ & $12.08 \pm 10.02(10)$ & 0.775 \\
\hline T2-T1 & $-11.11 \pm 25.44(-21.7)$ & $-15.28 \pm 15.51(-15)$ & \\
\hline
\end{tabular}

${ }^{1}$ Mann Whitney $U$ test; ${ }^{2}$ Wilcoxon sign test; ${ }^{*}<<0.05$. Aver: Average; SD: Standard Deviation; T0: before the lecture; T1: immediately after the lecture; T2: three months after the lecture.

Table 4. Statistical comparison of the average percentages of correct answers (\%) at the three time points and their differences according to the timing of delivery of information.

\begin{tabular}{llll}
\hline & \multicolumn{2}{l}{ Scores related with } & P1 \\
\cline { 2 - 3 } & First half of the lecture & Second half of the lecture & \\
\cline { 2 - 3 } & Aver \pm SD (median) & Aver \pm SD (median) & \multirow{2}{*}{0.868} \\
\hline T0 & $47.11 \pm 33.04(46.7)$ & $45.56 \pm 30.15(43.3)$ & 0.118 \\
\hline T1 & $78.89 \pm 24.09(86.7)$ & $67.78 \pm 23.76(70)$ & 0.589 \\
\hline T2 & $62.89 \pm 28.67(63.3)$ & $54.89 \pm 33.92(63.3)$ & \\
\hline T0/T1 & P2: $0.008^{*}$ & P2: $0.004^{*}$ & \\
\hline T0/T2 & P2: 0.125 & P2: $0.016^{*}$ & 0.589 \\
\hline T1/T2 & P2: $0.021^{*}$ & P2: $0.030^{*}$ & 0.819 \\
\hline T1-T0 & $31.78 \pm 37.22(26.7)$ & $22.22 \pm 20.11(26.7)$ & 0.983 \\
\hline T2-T0 & $15.78 \pm 29.07(6.7)$ & $9.33 \pm 11.63(10)$ & $-12.89 \pm 19.84(-16.7)$ \\
\hline T2-T1 & $-16 \pm 22.75(-13.3)$ & & \\
\hline
\end{tabular}

${ }^{1}$ Mann Whitney $U$ test; ${ }^{2}$ Wilcoxon sign test; " $p<0.05$. Aver: Average; SD: Standard Deviation; T0: before the lecture; T1: immediately after the lecture; T2: three months after the lecture.

\section{Discussion}

Senior dental students were selected in the present study as questionnaire participants as these students had taken the multidisciplinary dental traumatology course in the previous year, which enabled us to understand how helpful the course was in terms of implementation of knowledge. In a previous study, the assessment period for the retention of knowledge was selected as 6 months [2]. On the other hand, a shorter period of 3 months was preferred in the present investigation to provide a varying data to educators in terms of the repetition of knowledge. As this was a study on a voluntary basis, nearly $50 \%$ of the class accepted to participate, similar to some previous studies [4]. A lower number of participants were males which was compatible with the relatively lower number of male students enrolled in class. There was a significant increase in the knowledge following a $1 \mathrm{~h}$ lecture and retention after three months despite of some decrease. So, it can be 
concluded that it is beneficial to make a brief summary about dental trauma just before graduation.

Gender was found to have no influence on the number of correct answers at all periods. Five students who did not participate in the questionnaire given 3 months later were excluded from the study. Such exclusions and their reasons have not been reported in previous investigations.

Dental trauma is not a particular specialty and generally conducted with the collaboration of different departments involved in the discipline. A study performed in the UK revealed that dental trauma is the topic in which students feel the least self-confidence [30]. In the UK and Japan, students' knowledge has been found to be inadequate when dental trauma is concerned [4,31]. The results of the present study correlate with these findings as there is a necessity for students close to graduation to develop their knowledge in the management of dental trauma. Furthermore, the result of the present and the aforementioned study [4] indicate that lectures are reliable and effective means of improving the knowledge and retention of knowledge on trauma to the undergraduate dental student.

A $30 \mathrm{~min}$ [32] or $1 \mathrm{~h}$ lecture was shown to be helpful to improve the dental trauma knowledge of high-risk population i.e. army recruits [11], various professionals, such as elementary school teachers, physical education professionals, bank employees, dental doctors, and pediatricians [33]. A need for more studies to improve awareness and keeping dentists updated [34] about this topic is apparent [35]. Even implementing such lectures to the curriculum of sports schools is suggested [32].

There are various studies performed previously which aim to assess students' and general dental practitioners' knowledge on traumatic injuries. Some of these studies are limited to solely avulsion cases [25,36-39]. However, the concept of trauma encompasses a wide range of clinical conditions starting from a simple concussion, progressing towards more complex cases such as complicated crown fractures, crown-root fractures, intrusions, extrusions and alveolar injuries. Moreover, dental approach to traumatic cases varies depending on the stage of life of the affected individual and the majority of these incidents require a multidisciplinary approach. Although possession of knowledge is very significant when the dental discipline is concerned, retention of acquired knowledge is as important. Consequently, frequent reminders of topics might play an essential role in the refreshment of existing knowledge and extension of the correct professional attitude when encountered with real cases during practice. One clear conclusion obtained from the present study is the fact that acquired information gradually decreases over time, necessitating frequent reminder lectures. In a study performed in the UK, dental students of various educational backgrounds were subjected to a $1 \mathrm{~h}$ lecture, similar to the current study following which an improvement was detected in terms of the general knowledge on trauma. However, repetition of the questionnaire with a 6-month elapse revealed a general loss of existing information, emphasizing the necessity to perform frequent repetitions [4]. In the aforementioned study, participating students were categorized in terms of previous educational backgrounds, which is different than the present investigation. There were no variables in terms of previous education in the present study as all students were graduates of high schools, leading us to assume that the only parameter influencing the results is the lecture.

It has been reported that people remember $20 \%$ of what they read, $30 \%$ of what they hear, $40 \%$ of what they see, $50 \%$ of what they say, $60 \%$ of what they do and $90 \%$ of what they read, hear, see, say and do (http://www.ncl.ac.uk/students/ wellbeing/assets/documents/StudySkillsGuide.pdf). In the present study, six students had the opportunity to have experience on dental trauma. In contrast to the students with no previous experience, the increases in the average percentages of correct answers of the students with previous knowledge on trauma were not significant, showing that the differences cannot be attributed only to the lecture performed and emphasizing the influence of experience on overall knowledge. It is obvious that no matter how strong a theoretical knowledge you possess, actually observing a case in clinical practice is a very significant factor that contributes to overall competency in dental trauma. This implies the necessity of developing strategies and policies by dental schools so that students have more opportunities to be involved in the management of traumatic injuries.

Various studies reported a significant decrease of dental trauma knowledge in time $[20,40,41]$. On the other hand, two of these studies were performed on dentists and revealed a significant decrease especially 10 y after graduation [40,41]. These results can be attributed to insufficient and/or outdated information provided during the time they were educated. The results of these studies as well as the current study emphasize a need for refreshment about dental trauma right before graduation and repetitions on a regular basis. The retention was found to be sufficient on $3^{\text {rd }}$ and $12^{\text {th }}$ months by a research conducted on people with no dental education [32]. The level of information accepted to be satisfactory for dentists should be determined by authorities and aimed to be achieved.

It can also be clearly deduced from the findings of the present study that the possessed knowledge is time-limited consistent with the results of other reports $[4,42]$. It is noteworthy to mention that the present study lacks a control group and its results are limited to a restricted sample size and should be extrapolated with caution when making general statements. However, a general opinion is that retention of acquired knowledge is susceptible to time and it is quite likely for knowledge to be lost as time progresses $[43,44]$. The necessity and significance of the retention of knowledge in the management of dental trauma has been stressed by expressing the fact that educators continuously attempt to deliver concepts and topics that are applicable by attendees in the future [27]. This shows that undergraduate education by itself is unsatisfactory to confirm that knowledge of dental students on the management of trauma is retained throughout their professional lives and underlines the significance of continuous 
education [4]. The number of courses an individual has taken in a particular subject is reported to be a determinant of knowledge maintenance [45-47]. As AlZoubi et al. [4] suggested that dental trauma education should be held obligatory similar to Cardio-Pulmonary Resuscitation training (CPR), which is a mandatory course taken annually or biannually.

A variety of methods other than didactic teaching is available and may be beneficial to improve the retention of information $[48,49]$. Using online surveys may also help to increase the number of attending dentists and thus stronger evidence can be obtained. More studies incorporating various time periods should be conducted on this topic and, as stated by some authors, choosing an appropriate way i.e. internet, television etc. is recommended to reach target population [42].

Furthermore, it has been suggested that first aid in the management of dental trauma should be added among the continuous education programs conducted by the ministry of education [27]. This highlights the significance of educating the public on the management of dental trauma as emergency intervention should begin at the site of injury rather than the dental clinic [1]. The duty of a dental practitioner is not limited to the delivery of treatment but also includes the education of society on the prevention and management of these incidences [23]. Such an approach will decrease the prevalence of these undesirable accidents and will have a positive influence on the social costs of dental trauma.

\section{Conclusions}

A repetition before graduation is beneficial as senior dental students gave correct answers to less than half of the questions before lecture. After three months, students' level of knowledge was still higher than that of before lecture despite some decrease in the average percentage of correct answers in comparison to the one immediately after the lecture. The take home messages should be delivered in the second half of the lecture as more retention was observed when the information was delivered at this stage. The students who encountered no trauma cases previously may benefit more from a $1 \mathrm{~h}$ reminder lecture.

\section{Acknowledgement}

This work was supported by Scientific Research Projects Coordination Unit of Istanbul University. Project number: BEK-2017-24515.

\section{References}

1. Lam R. Epidemiology and outcomes of traumatic dental injuries: a review of the literature. Aust Dent J 2016; 61 Suppl 1: 4-20.

2. Glendor U. Epidemiology of traumatic dental injuries--a 12 year review of the literature. Dent Traumatol 2008; 24: 603-611.
3. Toprak ME, Tuna EB, Seymen F, Gençay K. Traumatic dental injuries in Turkish children, Istanbul. Dent Traumatol 2014; 30: 280-284.

4. AlZoubi F, Mannocci F, Newton T, Manoharan A, Djemal S. What do dental students know about trauma? Dent Traumatol 2015; 31: 482-486.

5. Emerich K, Wyszkowski J. Clinical practice: dental trauma. Eur J Pediatr 2010; 169: 1045-1050.

6. Lam R, Abbott P, Lloyd C, Lloyd C, Kruger E, Tennant M. Dental trauma in an Australian rural centre. Dent Traumatol 2008; 24: 663-670.

7. Bastone EB, Freer TJ, McNamara JR. Epidemiology of dental trauma: a review of the literature. Aust Dent J 2000; 45: 2-9.

8. Glendor U, Andersson L, Andreasen JO. Economic Aspects of traumatic dental injuries: textbook and colour atlas of traumatic injuries to the teeth (4th edn.) Blackwell Munksgaard, Copenhagen 2007; 217-223.

9. Borum MK, Andreasen JO. Therapeutic and economic implications of traumatic dental injuries in Denmark: an estimate based on 7,549 patients treated at a major trauma centre. Int J Paediatr Dent 2001; 11: 249-258.

10. Glendor U. On dental trauma in children and adolescents. Incidence, risk, treatment, time and costs. Swed Dent J Suppl 2000; 140: 1-52.

11. Levin L, Jeffet U, Zadik Y. The effect of short dental trauma lecture on knowledge of high-risk population: an intervention study of 336 young adults. Dent Traumatol 2010; 26: 86-89.

12. Levin L, Samorodnitzky GR, Schwartz-Arad D, Geiger SB. Dental and oral trauma during childhood and adolescence in Israel: occurrence, causes, and outcomes. Dent Traumatol 2007; 23: 356-359.

13. Levin L, Friedlander LD, Geiger SB. Dental and oral trauma and mouthguard use during sport activities in Israel. Dent Traumatol 2003; 19: 237-242.

14. Petersson EE, Andersson L, Sörensen S. Traumatic oral vs. non-oral injuries. Swed Dent J 1997; 21: 55-68.

15. Hamilton FA, Hill FJ, Holloway PJ. An investigation of dento-alveolar trauma and its treatment in an adolescent population. Part 2: Dentists knowledge of management methods and their perceptions of barriers to providing care. Br Dent J 1997; 182: 129-133.

16. Stewart SM, Mackie IC. Establishment and evaluation of a trauma clinic based in a primary care setting. Int J Paediatr Dent 2004; 14: 409-416.

17. Cowpe J, Plasschaert A, Harzer W, Vinkka-Puhakka H, Walmsley AD. Profile and competences for the graduating European dentist-update 2009. Eur J Dent Educ 2010; 14: 193-202.

18. Smith M, Lennon MA, Brook AH, Blinkhorn FA, Blinkhorn AS, Robinson PG. A randomised controlled trial of the effect of outreach placement on treatment planning by dental students. Br Dent J 2006; 201: 27-31. 
19. Smith M, Lennon MA, Brook AH, Ritucci L, Robinson PG. Student perspectives on their recent dental outreach placement experiences. Eur J Dent Educ 2006; 10: 80-86.

20. Kostopoulou MN, Duggal MS. A study into dentists knowledge of the treatment of traumatic injuries to young permanent incisors. Int J Paediatr Dent 2005; 15: 10-19.

21. Krastl G, Filippi A, Weiger R. German general dentists knowledge of dental trauma. Dent Traumatol 2009; 25: 88-91.

22. Zhao Y, Gong Y. Knowledge of emergency management of avulsed teeth: a survey of dentists in Beijing, China. Dent Traumatol 2010; 26: 281-284.

23. Baginska J, Wilczynska-Borawska M. Continuing dental education in the treatment of dental avulsion: Polish dentists knowledge of the current IADT guidelines. Eur J Dent Educ 2013; 17: 88-92.

24. Canar C, Atabek D, Alaasam A. Knowledge of dentists in the management of traumatic dental injuries in Ankara, Turkey. Oral Health Prev Dent 2013; 11: 23-30.

25. de Vasconcellos LG, Brentel AS, Vanderlei AD, de Vasconcellos LM, Valera MC, de Araujo MA. Knowledge of general dentists in the current guidelines for emergency treatment of avulsed teeth and dental trauma prevention. Dent Traumatol 2009; 25: 578-583.

26. Pedrini D, Panzarini SR, Poi WR, Sundefeld ML, Tiveron AR. Dentists level of knowledge of the treatment plans for periodontal ligament injuries after dentoalveolar trauma. Braz Oral Res 2011; 25: 307-313.

27. Raoof M, Shokouhinejad N, Izadi A, Nourzadeh M, Afkham A, Forghani FR, Tavallaie M, Mohammadalizadeh S. Long-term effect of an educational intervention regarding dental trauma first aid: a phase II study. Dent Traumatol 2014; 30: 296-301.

28. Andersson L, Andreasen JO, Day P, Heithersay G, Trope M, Diangelis AJ, Kenny DJ, Sigurdsson A, Bourguignon C, Flores MT, Hicks ML, Lenzi AR, Malmgren B, Moule AJ, Tsukiboshi M, International Association of Dental Traumatology. International Association of Dental Traumatology guidelines for the management of traumatic dental injuries: 2. Avulsion of permanent teeth. Dent Traumatol 2012; 28: 88-96.

29. Diangelis AJ, Andreasen JO, Ebeleseder KA, Kenny DJ, Trope M, Sigurdsson A, Andersson L, Bourguignon C, Flores MT, Hicks ML, Lenzi AR, Malmgren B, Moule AJ, Pohl Y, Tsukiboshi M; International Association of Dental Traumatology. International Association of Dental Traumatology guidelines for the management of traumatic dental injuries: 1. Fractures and luxations of permanent teeth. Dent Traumatol 2012; 28: 2-12.

30. Rodd HD, Farman M, Albadri S, Mackie IC. Undergraduate experience and self-assessed confidence in paediatric dentistry: comparison of three UK dental schools. Br Dent J 2010; 208: 221-225.

31. Fujita Y, Shiono Y, Maki K. Knowledge of emergency management of avulsed tooth among Japanese dental students. BMC Oral Health 2014; 14: 34.
32. Emerich K, Wlodarczyk P, Ziolkowski A. Education of Sport University students regarding first-aid procedures after dental trauma. Eur J Paediatr Dent 2013; 14: 37-41.

33. Frujeri Mde L, Costa ED. Effect of a single dental health education on the management of permanent avulsed teeth by different groups of professionals. Dent Traumatol 2009; 25: 262-271.

34. Emerich K, Nadolska-Gazda E. Dental trauma, prevention and knowledge concerning dental first-aid among Polish amateur boxers. J Sci Med Sport 2013; 16: 297-301.

35. Emerich K, Kaczmarek J. First aid for dental trauma caused by sports activities: state of knowledge, treatment and prevention. Sports Med 2010; 40: 361-366.

36. Upadhyay S, Rokaya D, Upadhayaya C. Knowledge of emergency management of avulsed teeth among general dentists in Kathmandu. Kathmandu Univ Med J (KUMJ) 2012; 10: 37-40.

37. Ulusoy AT, Onder H, Cetin B, Kaya S. Knowledge of medical hospital emergency physicians about the first-aid management of traumatic tooth avulsion. Int $\mathrm{J}$ Paediatr Dent 2012; 22: 211-216.

38. Westphalen VP, Martins WD, Deonizio MD, da Silva Neto UX, da Cunha CB, Fariniuk LF. Knowledge of general practitioners dentists about the emergency management of dental avulsion in Curitiba, Brazil. Dent Traumatol 2007; 23: 6-8.

39. Cohenca N, Forrest JL, Rotstein I. Knowledge of oral health professionals of treatment of avulsed teeth. Dent Traumatol 2006; 22: 296-301.

40. de Franca RI, Traebert J, de Lacerda JT. Brazilian dentists knowledge regarding immediate treatment of traumatic dental injuries. Dent Traumatol 2007; 23: 287-290.

41. Cauwels RG, Martens LC, Verbeeck RM. Educational background of Flemish dental practitioners and their perceptions of their management of dental trauma. Dent Traumatol 2014; 30: 133-139.

42. Al-Sane M, Bourisly N, Almulla T, Andersson L. Laypeoples preferred sources of health information on the emergency management of tooth avulsion. Dent Traumatol 2011; 27: 432-437.

43. Custers EJ. Long-term retention of basic science knowledge: a review study. Adv Health Sci Educ Theory Pract 2010; 15: 109-128.

44. Young LM, Anderson RP. The use of personal narrative in classroom case study analysis to improve long-term knowledge retention and cultivate professional qualities in Allied Health students. J Microbiol Biol Educ 2010; 11: 107-112.

45. Bahrick HP. Semantic memory content in permastore: fifty years of memory for Spanish learned in school. J Exp Psychol Gen 1984; 113: 1-29.

46. Bahrick HP, Hall LK. Lifetime maintenance of high school mathematics content. J Exp Psychol Gen 1991; 120: 20-33.

47. Conway MA, Cohen G, Stanhope N. On the very long-term retention of knowledge acquired through formal education: 
Twelve years of cognitive psychology. J Exp Psychol Gen 1991; 120: 395-409.

48. Robson N, Popat H, Richmond S, Farnell DJ. Effectiveness of an audience response system on orthodontic knowledge retention of undergraduate dental students-a randomised control trial. J Orthod 2015; 42: 307-314.

49. Mains TE, Cofrancesco J, Milner SM, Shah NG, Goldberg H. Do questions help? The impact of audience response systems on medical student learning: a randomised controlled trial. Postgrad Med J 2015; 91: 361-367.

\section{*Correspondence to}

Handan Ersev

Department of Endodontics

Faculty of Dentistry

Istanbul University

Turkey 